\title{
El nuevo orden discursivo de la extrema derecha española: de la deshumanización a los bulos en un corpus de tuits de Vox sobre la inmigración
}

The new discursive order of the Spanish extreme right: from deshumanization to fake news in a corpus of Vox Party tweets about immigration

RESUMEN: Las estrategias discursivas del heterogéneo campo político de la derecha radical a escala global presentan características coincidentes, entre las que destacan la provocación, la escandalización, la polarización y la diseminación de bulos a través de las redes sociales. Dentro de sus ejes programáticos, coinciden también en un fuerte rechazo a la inmigración. Con el fin de avanzar en el conocimiento de estos aspectos en el ámbito español, nos hemos fijado los siguientes objetivos: analizar el discurso de Vox sobre inmigrantes adultos y menores no acompañados en la red social Twitter aplicando las técnicas del análisis crítico y el análisis del discurso multimodal, y detectar algunos de los bulos más frecuentes sobre la población migrante que Vox disemina a través de esta red social. Para ello, se ha recopilado un corpus de tuits sobre dicha temática en las cuentas de los perfiles políticos más mediáticos y con mayor número de seguidores del partido, así como en su cuenta oficial, durante 15 meses, y se ha aplicado una metodología de análisis mixto, cuantitativo y cualitativo. Los resultados muestran las frecuencias generales de emisión de tuits sobre inmigración en las 5 cuentas analizadas, los diferentes ejes temáticos y las estrategias multimodales con los que Vox estigmatiza y deshumaniza a las personas migrantes, las colocaciones a las que recurre para ello y algunos de los bulos más frecuentes de su discurso antiinmigración. El trabajo concluye que uno de los pilares más importantes del orden discursivo de Vox es la fabricación de bulos para criminalizar y generar miedo en torno a la inmigración y normalizar así los mensajes de odio hacia este colectivo. 
Palabras clave: discurso político, Twitter, Vox, inmigración, redes sociales, bulos, racismo, discurso de odio, análisis crítico del discurso.

ABSTRACT: The discursive strategies of the heterogeneous political field of radical right on a global scale present coinciding characteristics, among which provocation, scandalization, polarization and the dissemination of hoaxes through social networks stand out. Likewise, within their programmatic axes, they coincide in a strong rejection of immigration. In order to advance our understanding of these aspects in Spain, we have set up the following aims: to analyze Vox's discourse on adult immigrants and unaccompanied minors on the social network Twitter applying the techniques of Critical Discourse Analysis and those of the Multimodal Discourse, and to detect some of the most recurrent fake news about the migrant population that Vox disseminates through this social network. In order to accomplish these objectives, a corpus of tweets on this issue has been compiled in the accounts of the most mediatic political profiles and with the largest number of followers of the party, as well as in its official account, for 15 months. Mixed methodology techniques, both quantitative and qualitative, have been applied. The results show the general frequencies of issuance of tweets about immigration in the 5 accounts analyzed, the different thematic axes and the multimodal strategies with which Vox stigmatizes and dehumanizes migrants, the collocations used by the party and some of the most frequent hoaxes of its anti-immigration discourse. The work concludes that one of the most important pillars of Vox's discursive order is the manufacture of hoaxes to criminalize and generate fear around immigration and thus normalize the hate speech towards this group.

Key words: political discourse, Twitter, Vox, immigration, social networks, fake news, racism, hate speech, Critical Discourse Analysis.

\section{INTRODUCCIÓN}

La irrupción a finales de 2018 en el panorama político institucional español de Vox, tras obtener casi un 11\% de los sufragios en las elecciones autonómicas andaluzas, pone punto final a la llamada excepción española (Alonso y Rovira Kaltwasser, 2015; González Enríquez, 2017) de casi cuarenta años, en los cuales ninguna fuerza de extrema derecha había logrado penetrar en las cámaras autonómicas o el Congreso desde la disolución de Fuerza Nueva en 1982. A diferencia de lo sucedido en el último periodo con el Rassemblement National francés, la Lega italiana, el Amanecer Dorado griego, la Fidesz - Unión Cívica Húngara de Orbán, la alemana AfD, el Partido por la Libertad en Países Bajos y el UKIP en Reino Unido, así como con los principales referentes de Vox en sus orígenes, el partido de Bolsonaro en Brasil o el Partido Ley y Justicia de Kaczynski en Polonia (Urbán, 2019: 82), el PP había logrado ser durante décadas la casa de toda la derecha española, cobijando en ella a su ala más radical. Como partido catch all del nacionalismo español conservador, el Partido Popular saturó durante cuarenta años ese espacio político, bloqueando la salida de su alma más ultraconservadora en lo moral y más marcadamente neoliberal en lo económico. 
Casi un año después de su entrada en el parlamento andaluz, Vox, convertido ya en una escisión exitosa del PP, se asienta contundentemente también en el Congreso como tercera fuerza política con 52 diputados, tras la repetición de las elecciones generales en noviembre de 2019, consiguiendo más del doble de escaños que en abril de ese mismo año y confirmando así que la extrema derecha había llegado para quedarse, tarde pero con fuerza, también a España. Para explicar el porqué de la eclosión de Vox en ese momento concreto, Urbán (2019: 80-81) plantea 6 factores que resumimos a continuación: 1) la crisis del PP por sus casos de corrupción; 2) la normalización del discurso de la ultraderecha por la competencia entre PP y Ciudadanos; 3) la ola mundial de ascenso de los nuevos populismos xenófobos; 4) el marco atrapalotodo del conflicto territorial catalán; 5) la controversia generada por la exhumación de los restos de Franco del Valle de Cuelgamuros y 6) las políticas de austeridad en el marco de la crisis económica global.

Los temas estrella de la agenda política de Vox no constituyen una novedad dado que, en su mayoría, son compartidos con los de los partidos anteriormente citados. Tampoco lo es que su principal fuente de inspiración comunicativa sea la alt-right (alternative right) estadounidense, con su referente mediático y gurú electoral, Steve Bannon, al frente. Comparten también una plena conciencia sobre el papel de los medios de comunicación clásicos hoy y sobre su pérdida de hegemonía como fuente de noticias frente internet, principal vía de acceso a la información para buena parte de la ciudadanía. En este sentido, el control de la comunicación política se ha convertido en una forma de ejercer el poder, especialmente para para las élites, interesadas en influir en las percepciones ciudadanas (Casero-Ripollés, 2009). No resulta extraño por tanto que en el Manual de Comunicación de Vox (2019) se afirme que las redes sociales son su principal canal de comunicación «porque tienen como ventaja que permiten transmitir nuestros mensajes sin ningún tipo de intermediación de los medios de comunicación. A los españoles les llegan nuestros mensajes tal como queremos nosotros»».

Debido a su mayor influencia en la agenda política y en los medios de comunicación ${ }^{1}$, la plataforma de microblogging Twitter es actualmente la red social de referencia en la política virtual (Jungherr, 2016; Mancera Rueda, 2020), y aunque los actores políticos no suelen establecer en esta red un diálogo real con sus electores o detractores (Alonso-Muñoz, Miquel-Segarra y Casero-Ripollés, 2016), Twitter sigue siendo el indiscutido protagonista de la comunicación política. Este esquema comunicativo de interacción directa, aunque no bidireccional, entre partidos políticos y sus seguidores ofrece un gran margen de maniobra para la manipulación de contenidos y la fabricación de fake news. En efecto, las prácticas de desinformación y manipulación están siendo reactivadas en el S. XXI por las fuerzas políticas de la far right a escala global, tras su utilización en el S. XX por parte del nazismo y el fascismo. Las noticias falsas son, como se verá en este trabajo, uno de los principales recursos de Vox para diseminar su ideario xenófobo. A través de ellas acusan diariamente a inmigrantes adultos y menores no acompañados de acaparar las ayudas sociales (paguitas), sembrar el caos y el terror en los barrios con atracos y violaciones (manadas) y de ser focos de contagio de Covid-19 desde el estallido de la pandemia (contagiados), como se verá en el análisis.

\footnotetext{
${ }^{1}$ Mancera Rueda (2020: 32) recoge los resultados de un estudio de la agencia de marketing digital Elogia que revelan, de acuerdo con una encuesta, que no es Facebook la red social considerada como «más politizada», sino Twitter: «Pese a que el número de usuarios de Twitter -en torno a los 320 millones- es mucho menor que el de sus competidoras -alrededor de 2.200 millones en el caso de Facebook, 2.000 en el de YouTube y 1.000 en el de Instagram-, su grado de influencia en la política y en los medios de comunicación es muy superior. Especialmente, a raíz de la campaña del presidente norteamericano Barack Obama» (ibíd.). Cabe destacar que de los cinco grandes partidos con representación institucional, Vox es el que menos seguidores tiene en Twitter.
} 
Si bien el debate sobre el encuadre ideológico de Vox excede con mucho los objetivos de este trabajo, conviene aclarar que en él se utilizan indistintamente extrema derecha, en línea con Urbán (2019) o Ramos (2021), y derecha radical, siguiendo el término acuñado por Pippa Norris (2005) y adoptado por Cas Mudde (2007), también propuesto como expresión más adecuada para referirse a Vox por Ferreira (2019) o Rubio-Pueyo (2019), entre otros. Cabe tener en cuenta que autores relevantes como Vampa (2020) y Santamarina (2020) consideran que Vox es in primis un partido perteneciente al espectro del populismo de derecha, por lo que también se considera dicha denominación. De hecho, aunque los distintos proyectos políticos de la derecha radical, la extrema derecha y los populismos excluyentes a escala global presentan diferencias entre sí, todos ellos comparten la fabricación de un escenario ficticio en el que se libra una batalla desigual contra poderosos enemigos que encarnan el mal y amenazan la supervivencia de valores patrióticos esenciales para la nación.

El nativismo es, en efecto, uno de los pilares ideológicos fundamentales dentro de este amplio y variado espectro ideológico, construido en torno al eje de separación entre nacionales y extranjeros con el fin de criminalizar a estos últimos (Ferreira, 2019). Como indica Urbán (2019: 113), «prácticamente la totalidad de las organizaciones de este heterogéneo ambiente político apunta a las y los inmigrantes, preferentemente pobres y no occidentales, como chivo expiatorio de una supuesta degradación socioeconómica y cultural». En esta lógica, la inmigración destaca como eje vertebrador del discurso político de Vox, dado que actúa como epifenómeno de otros problemas, como la cobertura de las prestaciones sociales y la viabilidad del Estado del bienestar, la economía y el desempleo - proyectadas desde la lógica de la escasez-, la delincuencia y la seguridad (Castro Martínez y Mo Groba, 2020, 42-44). Ramos (2021: 44-50) también contempla la inmigración como uno de los ejes centrales de la ideología de Vox, junto al nacionalismo, el revisionismo histórico, la islamofobia, la defensa de las fronteras, el programa económico neoliberal, el antifeminismo y el negacionismo del cambio el climático, varios de los cuales destacan por su componente anticontemporáneo.

Con el fin de analizar cómo construye y en qué basa este partido su discurso antiinmigración, se ha recogido durante 15 meses entre 2020 y 2021 un corpus de 262 tuits de las cuentas de sus perfiles políticos más mediáticos y con mayor número de seguidores: Santiago Abascal, presidente del partido y diputado en el Congreso, Iván Espinosa de los Monteros, portavoz en el Congreso, Macarena Olona, portavoz adjunta en el Congreso, Rocío Monasterio, candidata y diputada en la Asamblea de Madrid, así como la cuenta oficial del partido. Una vez recogido el corpus de tuits, se han perseguido los siguientes objetivos: 1) estudiar las estrategias discursivas y temáticas empleadas por Vox en sus mensajes sobre migrantes adultos y menores no acompañados, aplicando las técnicas del análisis crítico del discurso (ACD) (Van Dijk, 2000 y 2003; Wodak y Meyer, 2001) y del análisis del discurso multimodal (Van Leeuwen, 2015, Yus, 2020) y 2) detectar algunos de los bulos más frecuentes sobre la población migrante que disemina a través de la red social Twitter².

\footnotetext{
${ }^{2}$ Aunque por motivos de espacio no podrá tratarse aquí, conviene destacar por su importancia en la comunicación política y la diseminación de noticias falsas el papel de la red de mensajería instantánea WhatsApp, de amplísima difusión, prácticamente del 100\%, con unos niveles de descentralización extraordinariamente difíciles de controlar. WhatsApp ha sido reconocido públicamente como el mejor medio para la difusión de noticias por los responsables de comunicación del partido de Bolsonaro en Brasil y por el propio Manuel Mariscal, diputado en el Congreso y jefe de Comunicación de Vox, quien en una entrevista llegó a despreciar el papel de los medios tradicionales con estas palabras: «No necesitamos a los grandes medios. Te dan prestigio, pero para llegar a ese público que nos interesa y que vive pegado al móvil nos basta con las redes. En EE. UU. Donald Trump ganó sin el apoyo de los medios tradicionales. Y tenemos futuro porque no dependemos de ellos» (Terrasa, 2019).
} 


\section{NATIVISMO Y RACISMO EN EL NUEVO ORDEN DISCURSIVO DE VOX}

\subsection{EL NUEVO ORDEN DISCURSIVO DE VOX}

Si hay tres rasgos destacados en la forma de comunicar de la alt-right estadounidense que han sido plenamente incorporados por los responsables de las redes sociales con Manuel Mariscal Zabala, Vicesecretario de Comunicación de Vox, al frente de la estrategia, estos son la incorrección política, el discurso antiestablishment y la priorización de la comunicación política a través de las redes sociales. La actividad de Vox en dichas redes se ha convertido en un elemento central en su estrategia y hoy es «el partido político que más seguidores tiene en Instagram (481.803) desbancando a Podemos (210.967) y cuadruplicando las cifras de Ciudadanos, el Partido Popular y el PSOE» (Aladro y Requeijo 2020: 205). Su actividad en Twitter, red social objeto de este estudio, es frenética, y desde ella Vox lanza campañas prácticamente a diario logrando un número muy elevado de interacciones y consiguiendo trending topics. Gracias a una amplia red de colaboradores, cuentas falsas y bots conectados a través de webs y foros extremistas, como Periodista Digital, Caso Aislado, Forocoches, Bolsomanía y el periódico digital Okdiario, de donde a menudo extraen bulos de naturaleza diversa que viralizan, se han articulado de forma muy similar a como lo hace la alt-right en EEUU (Hernández Conde y Fernández García, 2019).

La polarización, la provocación y la escandalización, habituales en dichas campañas, amplifican el efecto de sus mensajes en las redes, logrando a menudo marcar la agenda política y dar la batalla cultural a la izquierda. Entre la ultraderecha norteamericana, estas guerras culturales se libran -como explicó Nagle (2018) en Muerte a los normies - de forma muy especial en Twitter, donde el derecho al free spech en las interacciones de los seguidores de este espectro político les lleva a legitimar todo tipo de expresiones homófobas, sexistas, racistas y xenófobas, dado que el único objetivo es la caza de brujas, no ganar la batalla de las ideas. En la misma línea se expresaba recientemente del Teso (2020), cuando afirmaba que el grupo con más capacidad de provocar actualmente ese efecto en España es Vox y «a eso obedece también su presencia en los gangs, esa especie de bandas de Twitter». Esto forma parte de la estrategia de movilizar apelando a factores emocionales: la constante referencia a España «como patria y nación ancestral en lo ideológico se dirige a las emociones, no a la razón. Apela a las pasiones para movilizar a un electorado» (Fernández Riquelme 2020: 99), todo lo cual ha provocado que hayan obtenido mayor notoriedad y ampliado la audiencia de su mensaje político, antes minoritario. Como señala Peytibi (apud Alonso, 2020), Vox se presenta como «el pueblo [...] el resto son enemigos. 'Si no estás conmigo, estás contra el país'», todo ello usando un lenguaje directo, sencillo, con una adjetivación plana pero llamativa.

Este conglomerado de provocación permanente, de batalla a la corrección política, guerrillas en las redes sociales coordinadas con foros y webs, visceralidad discursiva, lenguaje directo y fabricación y difusión de bulos forma parte de un nuevo orden discursivo -denominación de Martín Rojo y Elvira Ruiz (2019) en su reciente aportación de referencia- que Vox ha sabido capitalizar en la política española de los últimos años. La foto del encabezado de la cuenta de Twitter del partido, @vox_es, es un buen compendio de todo lo dicho hasta aquí: 


\section{Imagen 1. Cabecera de la cuenta oficial de Twitter de Vox}

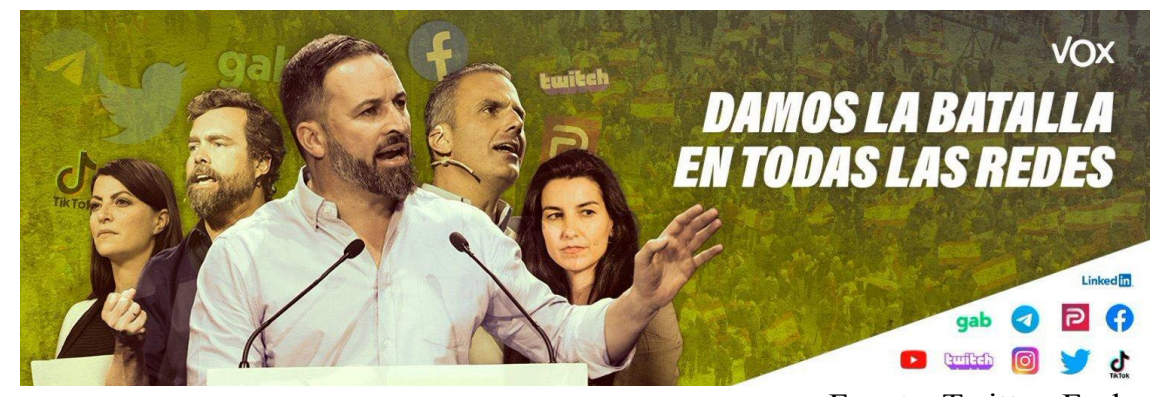

Fuente: Twitter. Fecha: 29/03/2021

\subsection{NATIVISMO, ISLAMOFOBIA, RACISMO Y DISCURSO ANTIINMIGRACIÓN}

La islamofobia y el discurso contra la inmigración no son elementos novedosos en el discurso de la derecha populista (Wodak, 2015), pero han ido afianzándose después de los atentados 11-S a nivel mundial (Cervi, 2020), tras el 11-M a nivel europeo, y con posterioridad a los atentados de La Rambla de Barcelona en agosto de 2017 en España. Cronológicamente, este último momento coincide con la incorporación de Manuel Mariscal, actual jefe de comunicación de Vox y antiguo community manager de Esperanza Aguirre, como responsable de la cuenta de Abascal, desde la cual orquestó tras los atentados la primera campaña de fuerte contenido islamófobo criminalizadora de los inmigrantes, a quienes se responsabilizó de los mismos ${ }^{3}$.

En líneas generales, el ideario antiinmigración de Vox gira en torno al ya mencionado eje del nativismo y la contraposición entre nacionales y extranjeros, especialmente de los pobres no occidentales, ecuación excluyente también clasista. Como se verá en el análisis, el discurso de Vox incide una y otra vez en la existencia de una supuesta invasión migratoria que tiene relación directa con el aumento de la inseguridad ciudadana, razón por la que justifican no solo que los inmigrantes estén exentos de derechos, sino que los no regularizados sean deportados junto a los regulares que hayan cometido algún delito. Otra de sus medidas más polémicas es el endurecimiento de las penas para «las mafias de la inmigración ilegal, así como para quienes colaboren con ellas, ya sean ONG, empresas o particulares» (100 medidas de Vox, 2018), marco en el cual se encuadran las campañas orquestadas por Rubén Pulido@rubnpulido, exsecretario de prensa y comunicación de Vox Andalucía. Considerado especialista en inmigración ilegal (sic@ivanedlm, ver tuit a continuación), Pulido trabajó para Salvini en las campañas antiinmigración italianas siendo uno de sus principales activos fabricando noticias falsas. Trabajando para Vox, cuenta, de hecho, con varias suspensiones de su cuenta en Twitter debido a la fabricación y difusión de bulos en torno a las personas migrantes:

\footnotetext{
3 La primera campaña islamófoba tuvo lugar en las elecciones municipales de 2011 de la mano de Plataforma per Catalunya, con el tristemente famoso vídeo de las niñas saltando a la comba. Dos de sus ideólogos son actualmente miembros de Vox y están siendo juzgados por su responsabilidad en ella.
} 
Imagen 2. Limitaciones y bloqueos de cuentas de Vox por parte de Twitter tras la emisión reiterada de bulos sobre la inmigración

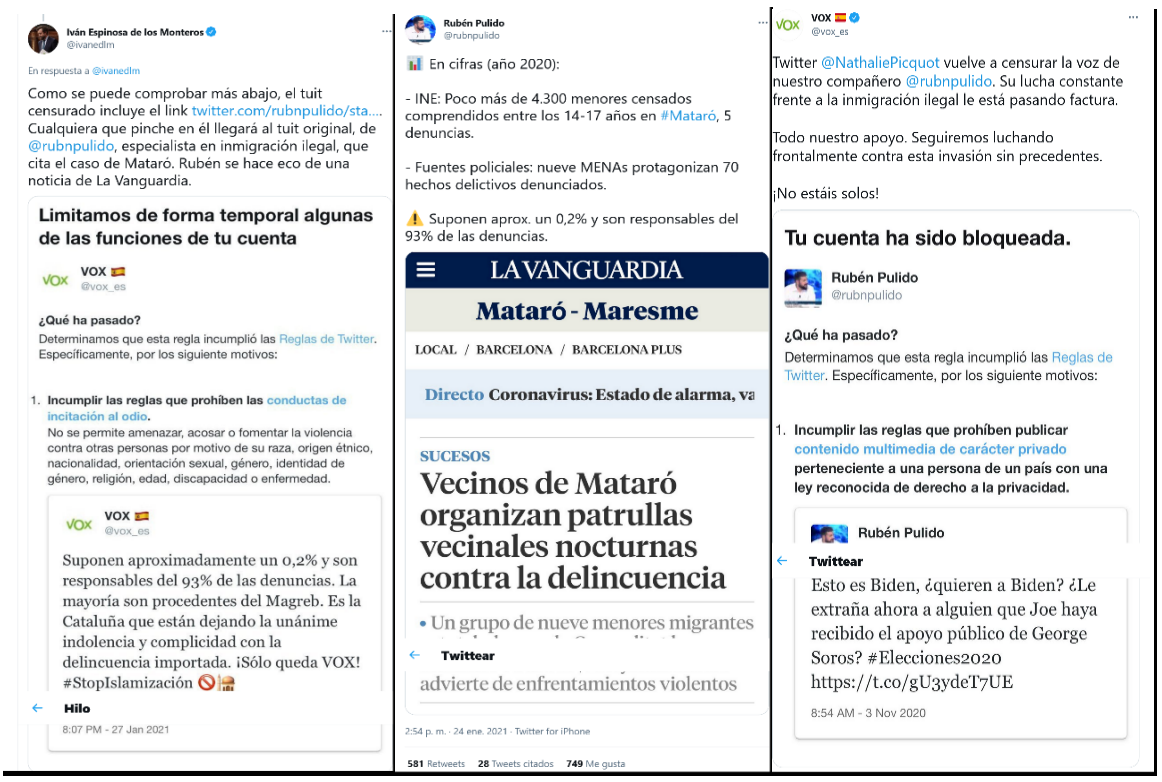

Fuente: Twitter. Fecha: 12/02/2021

De la mano de estas ideas, el discurso securitario tanto en las fronteras como en el interior se convierte en otro de los elementos centrales en la propaganda digital de Vox. Los inmigrantes para Vox no solo son, por tanto, chivos expiatorios de la crisis económica y sistémica, sino que a partir de su constante estigmatización actúan como límite a partir del cual se traza la frontera entre quienes deben ser protegidos y quienes no merecen ninguna protección (Urbán, 2019: 113).

Otro elemento característico de su discurso nativista y excluyente es el ataque a las niñas y niños que migran solos (Acha, 2021), los menores extranjeros no acompañados, llamados menas. El análisis de Cheddadi (2020) sobre una muestra de 62 tuits de 4 cuentas de Vox en 2019 en torno a estos menores resulta revelador. En él, llega a tres conclusiones sobre los argumentos utilizados para construir una narrativa sobre los menores migrantes: a) «Mena» como parte de una deriva «progre» contraria a la «España Viva»; b) Guerra al asistencialismo social universal: en defensa de un Estado Social nativista; c) Cuestión de seguridad: defender los barrios de los intrusos (Cheddadi, 2020: 70-71).

En nuestro corpus de 262 tuits, la frecuencia de mensajes directos sobre inmigrantes y menas, con colocaciones de adjetivación repetitiva y opiniones polémicas para provocar un alto tráfico de respuestas y lograr así una mayor difusión de sus noticias, alcanza casi el $100 \%$ de los casos. De igual modo, abundan en ellos la polarización a través de la narrativa de héroes y villanos con ejes reduccionistas y generalizaciones, como el más general legal-ilegal y otros más actuales, la asociación a la delincuencia o la exclusión de derechos, ejes ya señalados por Bañón Hernández (2002) en su estudio general sobre discurso e inmigración y también por Casero-Ripollés (2007) para las noticias sobre la inmigración en el periódico El País. Asimismo, como demostraron en investigaciones pioneras Martín Rojo y Van Dijk (1998) y más adelante Rubio Carbonero (2011), en la comunicación política del Partido Popular sobre los inmigrantes ya era recurrente la presentación negativa de los Otros (los inmigrantes ilegales que crean alarma social) frente a la presentación positiva del Nosotros (los españoles de bien). 


\section{METODOLOGÍA}

La metodología de este trabajo presenta un enfoque mixto cualitativo y cuantitativo, además del anclaje en los postulados del análisis crítico del discurso (Van Dijk 2000 y 2003; Wodak y Meyer, 2001) y en el análisis del discurso multimodal (Van Leeuwen, 2015; Yus, 2019). Esta metodología mixta se ha probado exitosa para los estudios sobre ACD, tal como recoge Pardo Abril (2013: 91-92) al describir los 4 pasos metodológicos habituales en este campo: 1) recolección del corpus; 2) análisis y sistematización del corpus con técnicas cuantitativas; 3) análisis cualitativo; 4) análisis crítico-interpretativo.

En esta investigación, se compiló, en primer lugar, el corpus en las 5 cuentas de Twitter de los perfiles políticos más destacados en esta red social: Abascal @santi_Abascal (570,2K seguidores), Espinosa de los Monteros @ivanedlm (308,2K), Olona@Macarena_Olona $(273,7 \mathrm{~K})$, Monasterio@monasterioR $(238,5 \mathrm{~K})$ y la cuenta oficial del partido $@$ vox_es $(437 \mathrm{~K})^{4}$ desde el 1 de enero de 2020 hasta el 29 de marzo de 2021. La elección de este lapso temporal vino motivada por dos hechos: analizar el tipo de discurso sobre la inmigración desplegado en el contexto de tres campañas electorales autonómicas, la de Galicia, País Vasco y Catalunya más la precampaña de Madrid, y una moción de censura, la presentada por Vox en el Congreso en octubre de 2020; y aportar nuevas evidencias al citado trabajo sobre los menas en 4 cuentas de Twitter de figuras políticas relevantes de Vox a lo largo de 2019, realizado por Cheddadi (2020). El lapso de tiempo es de 1 año, 2 meses y 29 días. Los pasos seguidos para la recogida del corpus fueron: $1^{\circ}$ ) búsqueda avanzada en Twitter en las 5 cuentas citadas filtrando por tres palabras exactas: inmigración, inmigrantes y menas, siempre en plural. Coincidiendo con lo señalado por Martín Rojo y Van Dijk (1998), no se menciona a inmigrantes individuales, pues estos son descritos como una masa homogénea. La lengua seleccionada para la búsqueda ha sido el español, lengua hegemónica en los perfiles de Vox en Twitter (Méndez Santos, 2020). El resultado de dicha búsqueda es de 262 tuits. $2^{\circ}$ ) Copiado manual y numeración de los 262 ítems en documento aparte con entradas diferenciadas para cada emisor con el fin de clasificar la muestra, incluyendo los enlaces a las noticias y añadiendo marcas de vídeo, fotos, documentos cuando los había por su relevancia para el análisis multimodal, así como captura de la imagen del tuit completa en algunos casos.

Una vez compilado el corpus, se procedió al copiado solo del texto de los tuits en una hoja de Excel para extraer frecuencias y facilitar una estadística básica que permitiera observar tendencias en las colocaciones más frecuentes de los tuits sobre inmigrantes y menores no acompañados, a partir de las cuales realizar el análisis cualitativo de forma ordenada. Finalmente, se realizó el análisis crítico-interpretativo de los datos y la detección de los bulos más frecuentes sobre el tema objeto del estudio. Presentamos a continuación los totales obtenidos ordenados en la tabla 1:

\footnotetext{
${ }^{4}$ Seguidores de las cuentas a fecha de envío del artículo. La decisión de dejar fuera del trabajo al Secretario General del partido y diputado en el Congreso, Javier Ortega-Smith, vino motivada por tener menos seguidores en Twitter y una actividad sustancialmente más baja que el resto de perfiles analizados.
} 
Tabla 1. Producción total de tuits sobre inmigración en 5 cuentas de Vox

\begin{tabular}{|c|c|}
\hline @vox_es & 161 \\
\hline @ivanedlm & 32 \\
\hline @santi_Abascal & 25 \\
\hline @monasterioR & 24 \\
\hline @macarena_olona & 20 \\
\hline Total & $\mathbf{2 6 2}$ \\
\hline
\end{tabular}

Fecha: 1/01/2020 a 29/03/2021

\section{ESTRATEGIAS DISCURSIVAS PARA LA DESHUMANIZACIÓN DE LAS PERSONAS MIGRANTES}

Para realizar el análisis cualitativo, se agruparon en ejes temáticos los tuits de las 5 cuentas a través de las formas lingüísticas nominales y adjetivales utilizadas, su relación con la confrontación exogrupo vs. endogrupo y las infografías de mayor impacto para observar cómo todo ello repercute en la deshumanización de las personas migrantes. En cuanto a los números generales, destaca el hecho de que la cuenta oficial, @vox_es, produzca 5 veces más tuits sobre el tema estudiado que el segundo, que no es el líder del partido, sino su portavoz en el Congreso, Espinosa de los Monteros, con diferencias casi inapreciables entre Abascal, Monasterio y Olona. Un aspecto también destacable cuantitativamente es la práctica total ausencia de tuits con solo texto en la mayor parte de la muestra, lo cual permite apreciar una característica comunicativa propia de los perfiles de Twitter de Vox diferente a la de otras personalidades políticas digitales: el 76,7\% de los tuits de la muestra lleva vídeos, memes, noticias de diarios generalistas (principalmente, del diario El Mundo), de medios afines o de la web del partido, otros tuits insertos, hilos, fotos..., hasta tal punto que los tuits con solo texto son excepcionales en todos los perfiles analizados, concentrándose la mayoría de ellos en la cuenta de Espinosa de los Monteros. Esto lleva a concluir, como se verá en la tabla 2, que las personalidades digitales individuales están supeditadas a la estrategia comunicativa del partido y que la multimodalidad es una característica perseguida por los responsables de las redes sociales de Vox, al menos en todo lo relativo a la difusión de su discurso sobre la inmigración. Veamos dos ejemplos: 


\section{Imagen 3. Deshumanización y estigmatización en tuits multimodales}

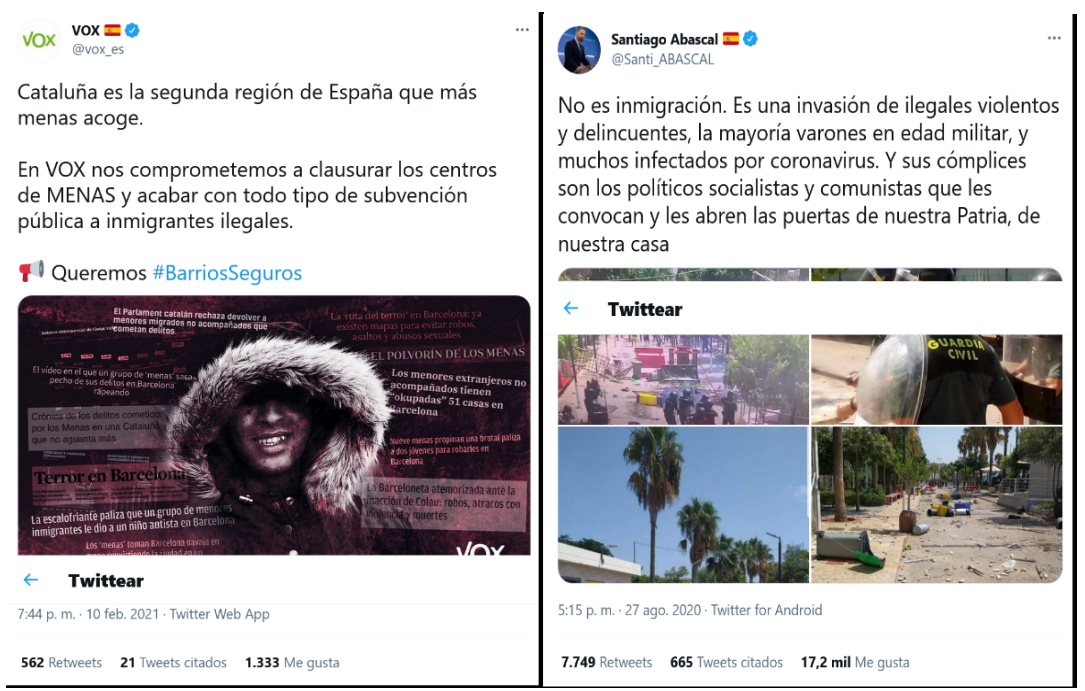

Fuente: Twitter. Fecha: 12/02/2021

Como se observa en el tuit multimodal de la cuenta oficial, el meme que se viralizó con la campaña \#BarriosSeguros de la izquierda presenta a un menor sin ojos ni mirada (lo primero que miramos al observar el rostro de un ser humano), con los dientes afilados, una sonrisa malévola y lo que parece una verruga o herida en el extremo superior de su cara. Todo ello contribuye a amplificar la fuerza ilocutiva de los distintos mensajes criminalizadores -supuestos titulares de prensa- que rodean al chico, a la vez que ofrecen una imagen deshumanizada y violenta de un fabricado arquetipo. En el tuit multimodal de la cuenta de Abascal a la derecha, vemos también fotos de los efectos de la violencia callejera perpetrada, supuestamente, por migrantes que son enfrentados por la guardia civil, varones en edad militar, y muchos infectados por coronavirus, en donde la estigmatización sin pruebas es tan evidente que no necesita de mayor explicación. Las imágenes e infografías diversas de los tuits de Vox cumplen siempre la función de amplificar el significado textual, en consonancia con lo señalado por Yus (2019: 19) en su estudio sobre 100 memes obtenidos de internet a través de una búsqueda aleatoria.

Tabla 2. Producción total de tuits multimodales en la muestra analizada

\begin{tabular}{|c|c|}
\hline @vox_es & 114 \\
\hline @ivanedlm & 21 \\
\hline @santi_Abascal & 23 \\
\hline @monasterioR & 24 \\
\hline @macarena_olona & 19 \\
\hline $\begin{array}{c}\text { Total / } \\
\text { \% del total de la } \\
\text { muestra }\end{array}$ & $\mathbf{2 0 1 /}$ \\
$\mathbf{7 6 , 7 \%}$
\end{tabular}




\subsection{EJES TELEMÁTICOS DEL DISCURSO XENÓFOBO Y ANTIINMIGRACIÓN DE VOX}

Los 6 temas que Vox repite como parte de su estrategia de criminalización y deshumanización de los migrantes adultos y menores no acompañados en Twitter son los siguientes, y alcanzan en el corpus de este estudio los números totales presentados en la tabla 3. Para dicha cuantificación, nos hemos servido de búsquedas a partir de las raíces de las colocaciones más repetidas en los mensajes de la muestra (ver apartado 4.2). La aparición de temas distintos en un solo tuit, vista en los ejemplos mostrados y en los que se ofrecen a continuación, supone que los totales temáticos sean más altos que los totales generales de la tabla 1.

\section{Imagen 4. Ejes temáticos racistas, multimodalidad y criminalización}

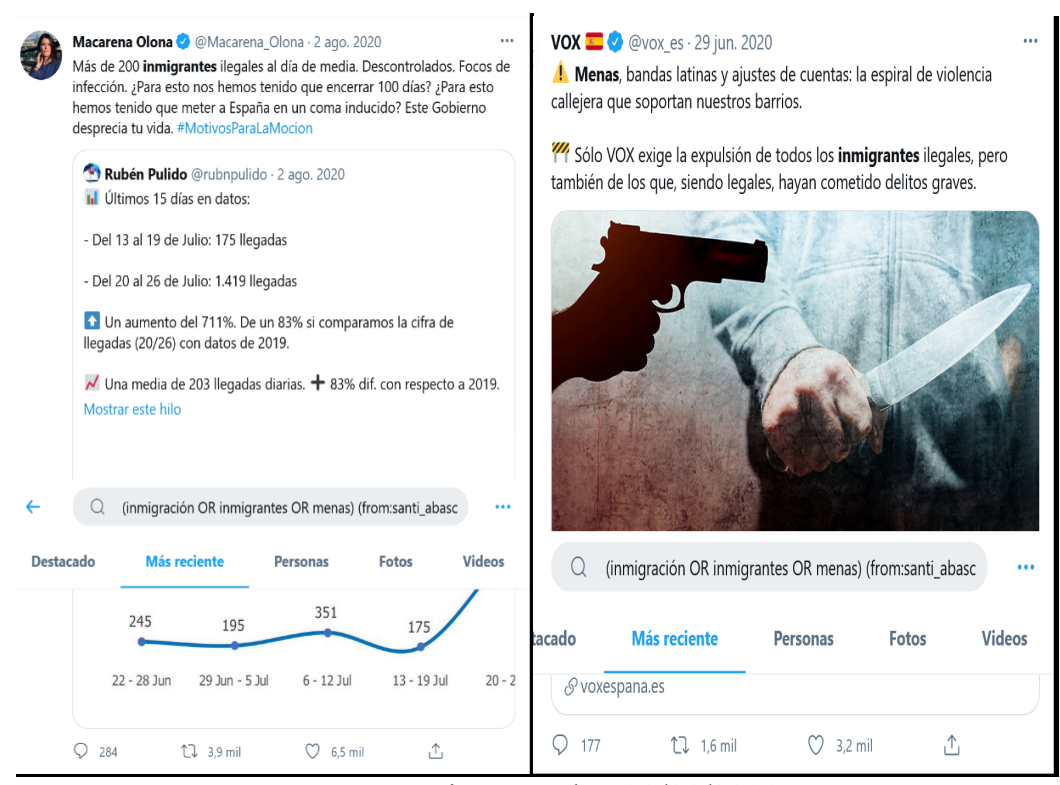

Fuente: Twitter. Fecha: 20/11/2020

Tabla 3. Ejes temáticos del discurso racista y antiinmigración en la muestra

\begin{tabular}{|c|c|c|c|c|c|c|}
\hline $\begin{array}{c}\text { Ejes del discurso } \\
\text { xenófobo }\end{array}$ & $\begin{array}{c}\text { Inmigrantes } \\
\text { ilegales }\end{array}$ & $\begin{array}{c}\text { Menas } \\
\text { agresores } y \\
\text { violadores }\end{array}$ & $\begin{array}{c}\text { Inmigrantes } \\
\text { delincuentes } y \\
\text { violentos }\end{array}$ & $\begin{array}{c}\text { Inmigrantes } \\
\text { invasores }\end{array}$ & $\begin{array}{c}\text { Inmigrantes } y \\
\text { focos de } \\
\text { contagio de } \\
\text { Covid-19 }\end{array}$ & $\begin{array}{c}\text { Inmigrantes } \\
\text { adultos y menas } \\
\text { perceptores del } \\
\text { subvenciones } y \\
\text { del IMV }\end{array}$ \\
\hline Total & 192 & 146 & 52 & 40 & 22 & 10 \\
\hline
\end{tabular}

Los temas predilectos en los mensajes sobre la inmigración de Vox son su ilegalidad (recuérdese que entre las 100 medidas se encuentra la deportación de los irregulares y de los regulares que cometan delitos) y los menas como responsables de la inseguridad en los barrios. Aunque no se han extraído para este trabajo los ejes temáticos cuenta a cuenta, cabe destacar que en el periodo de tiempo analizado los tuits del perfil de Rocío Monasterio giran en un $80,7 \%$ de los casos en torno al eje de los menas 
agresores y violadores. Llama la atención que para la construcción multimodal de los tuits de la candidata de Vox a la Comunidad de Madrid mostrados a continuación, separados por 2 meses y 9 días, se haya utilizado la misma foto de un escenario con rastros de violencia por parte del periódico El Mundo. La repetición no solo textual, sino también de imágenes, es otra constante del discurso digital de Vox:

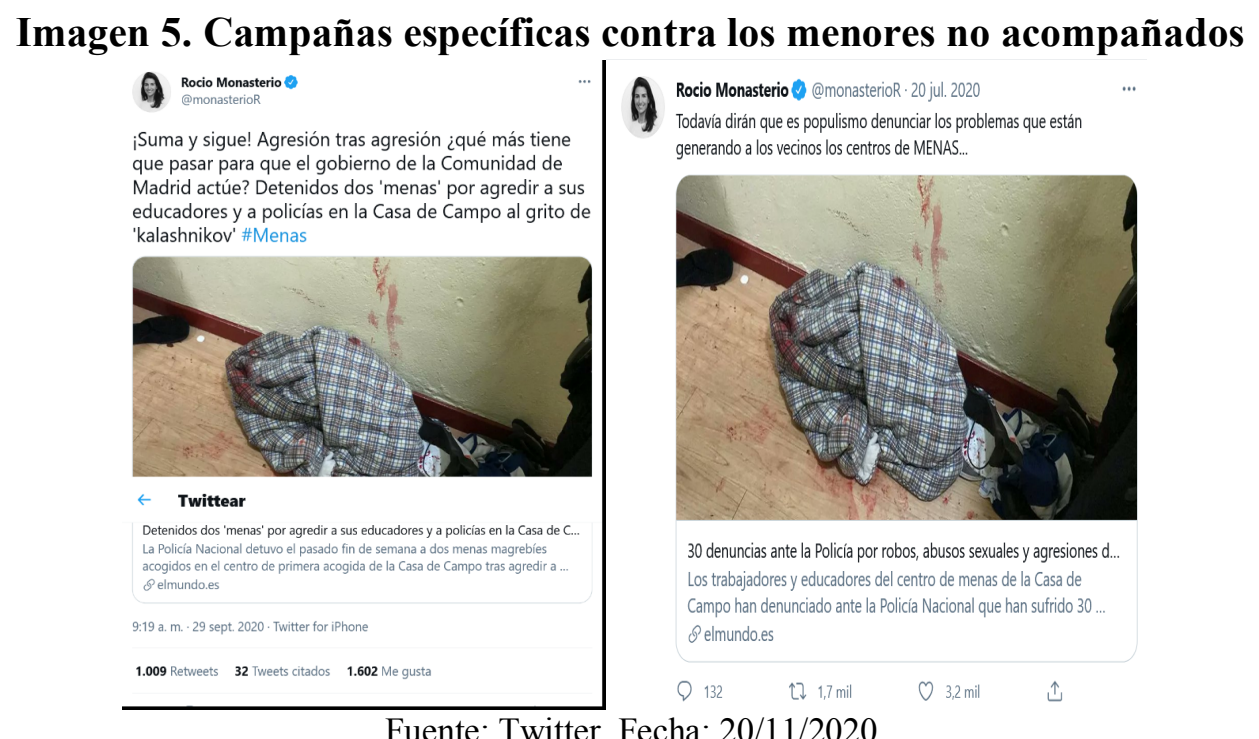

\subsection{ESTRATEGIAS DISCURSIVAS PARA LA DESHUMANIZACIÓN DE LAS PERSONAS MIGRANTES}

La creación de un nuevo repertorio de colocaciones (Barrios Rodríguez, 2015) nominales, adjetivales y aditivas, a través de la repetición constante de los mismos significantes colocados en el mismo orden, forma parte de la estrategia comunicativa de Vox en Twitter, que recurre a la generalización como forma de generar imaginarios de miedo y odio hacia las personas migrantes. El análisis cualitativo del corpus permite observar cómo cada uno de los ejes temáticos lleva asociada una serie de colocaciones fijas que aparecen repetitivamente, con la intención de automatizar en los receptores una imagen de los inmigrantes y los menores no acompañados inequívocamente ligada a la ilegalidad, la violencia, la invasión del país, la pandemia y la percepción de ayudas del estado que no les corresponden ${ }^{5}$ :

1. Inmigrantes ilegales: inmigración ilegal, inmigrantes ilegales, los ilegales.

2. Menas agresores y violadores: ataques de menas, centro de menas, grupos (peligrosos) de menas, violaciones en manada, ataques en manada, menas e ilegales, delincuentes y menas, menas y okupas, menas y narcotraficantes.

\footnotetext{
${ }^{5}$ Durante la campaña de las elecciones autonómicas a la Comunidad de Madrid del 4 de mayo de 2021, Rocío Monasterio, candidata a la presidencia de la Comunidad, hizo de los menores no acompañados protagonistas de todos sus discursos centrándose especialmente en los temas de la inseguridad ciudadana y las subvenciones. El final de esta campaña estuvo marcado por el cartel de Vox en la estación de metro de la céntrica Puerta del Sol que fue denunciado por la Fiscalía de Madrid por presunto delito de odio. En él aparecía la imagen de un supuesto "mena" frente a la de una mujer mayor, con el siguiente texto: Un mena, 4700 euros al mes. Tu abuela, 426 euros de pensión/mes. A pesar de que se confirmó que esta información era un bulo, la jueza del juzgado de guardia rechazó la petición de cautelares y no ordenó su retirada: https://cadenaser.com/ser/2021/04/22/tribunales/1619116237_486383.html.
} 
3. Inmigrantes delincuentes y violentos: delincuencia e inmigración, violencia y caos, violentos y maltratadores, inmigrantes violadores.

4. Inmigrantes invasores: invasión migratoria, invasión de ilegales, efecto llamada, invasión permanente, invasión sin precedentes, inmigración masiva e ilegal.

5. Inmigrantes focos de contagio de Covid-19: ilegales contagiados, inmigrantes contagiados.

6. Inmigrantes adultos y menas perceptores de subvenciones y del Ingreso Mínimo Vital: paguita clientelar, paguitas a los menas, subvención a la inmigración ilegal, subvención pública a inmigrantes ilegales, ingreso mínimo vital a inmigrantes.

Este repertorio de adjetivación y nominalización ofensiva y agresiva contribuye claramente a la deshumanización de las personas migrantes y constituye una incitación al odio e incluso a reacciones violentas, como las que tuvieron lugar en diversos centros de acogida en Canarias o en centros de menores de barrios como el de Hortaleza (Madrid), con la escalada de ataques producida entre octubre y noviembre de 2019 que desembocó en el lanzamiento de una granada el 4 de diciembre de ese mismo año. Puede verse también que en la ya clásica polarización entre el exogrupo y endogrupo, los otros, las personas migrantes, son presentadas como los seres no humanos. De acuerdo con Bello Reguera (2008: 17), mediante esta distinción el nosotros del emisor, en este caso Vox y sus portavoces, hace dos cosas: (a) se incluye a sí mismo en la humanidad normativa, con lo cual se humaniza a sí mismo, y (b) excluye de ella a los otros, con lo cual los deshumaniza. La comunicación multimodal contribuye a estos efectos, como se observa en el siguiente meme utilizado en varias campañas de Vox sobre la llamada invasión migratoria:

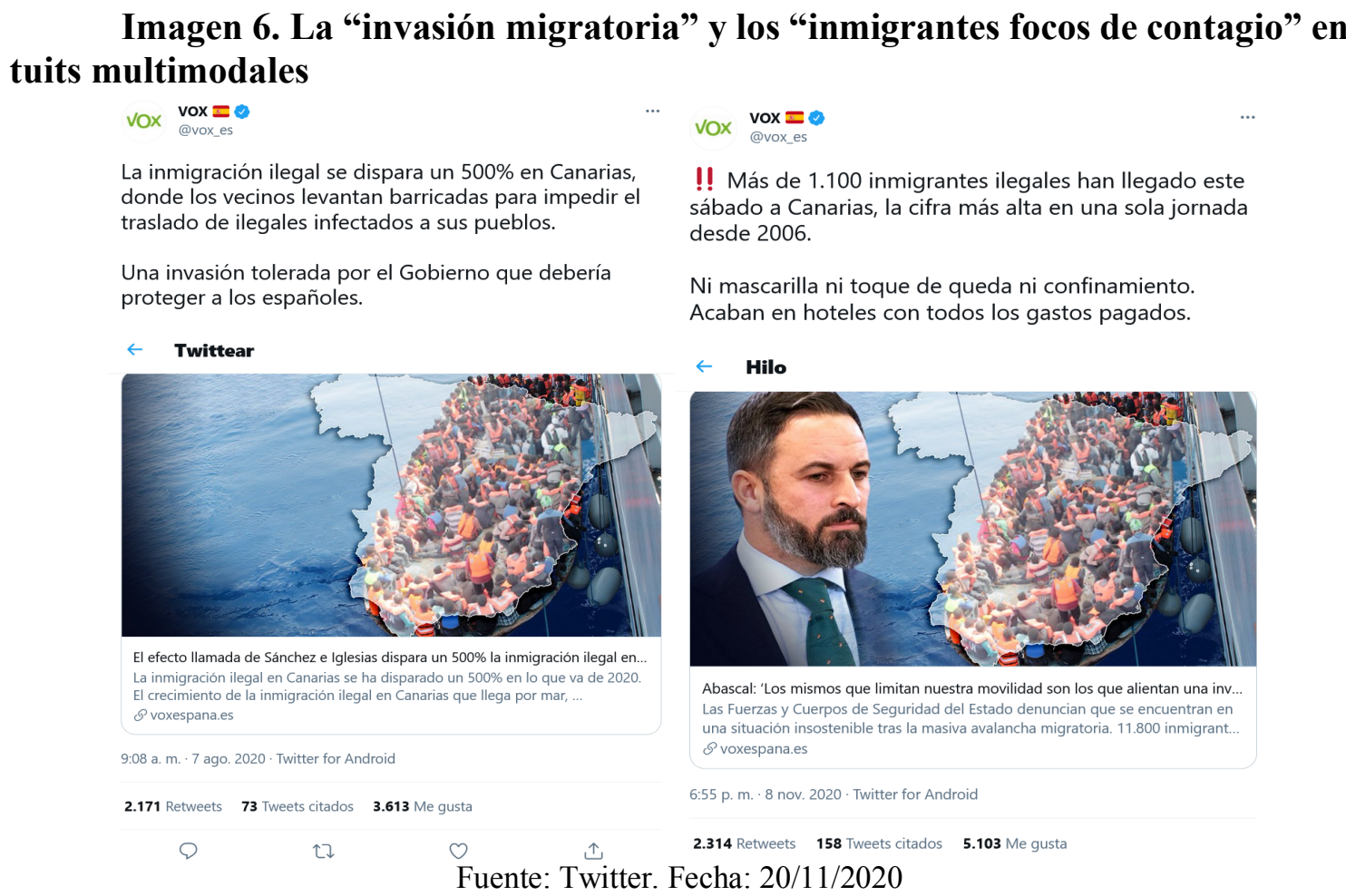




\subsubsection{La fábrica de bulos}

La fabricación de noticias falsas y su diseminación con efecto amplificado a través de sus redes sociales es otro rasgo que caracteriza el nuevo orden discursivo impulsado por la extrema derecha española. Estas publicaciones virales, basadas en historias ficticias con apariencia de noticias reales, se hicieron muy populares en EEUU bajo la denominación de fake news a partir de la victoria de Trump en 2016, pero están ya muy presentes en el contexto europeo:

En la actualidad -y de manera impune- se diseñan y emiten con la intención deliberada de intoxicación, de creación de miedos y alarmas sociales, de engañar e inducir a error, de manipular decisiones personales, desprestigiar o enaltecer a una institución, entidad o persona, como arma política para obtener réditos electorales, por ganancias económicas o a fin de enaltecer valores existenciales, entre otros muchos objetivos.

(Checa y Olmos, 2020: 31)

Los bulos han sido la estrategia con la que Vox, que como hemos visto renegaba en sus inicios de los grandes medios de comunicación, más ha buscado preservar su alma outsider a través de la escandalización y la consiguiente viralización de sus contenidos en las redes. Los inmigrantes han sido puestos en la diana por parte de la organización de extrema derecha a la hora de fabricar noticias falsas, construidas desde la óptica del racismo y la xenofobia con la intención de criminalizarlos. Los bulos de Vox en Twitter sobre los 6 ejes temáticos hallados en nuestra muestra se centran en el eje 3 (inmigrantes delincuentes y violentos) y en el eje 6 (inmigrantes y menas perceptores de subvenciones). El eje 4 sobre la invasión migratoria domina en las cuentas de Abascal y en la cuenta oficial.

Para desmontar estos bulos, resultan de gran utilidad las publicaciones de la página Maldita.es ${ }^{6}$, estudios como el de Fanjul y Gálvez-Iniesta (2020), que demuestran que el $80 \%$ de los migrantes llegan a España procedentes de América en avión y son, mayoritariamente, mujeres (desarticulando así el bulo y las imágenes de la invasión migratoria africana en pateras y el de los adultos en edad militar), y algunas webs de organismos gubernamentales. En cuanto a la percepción del ingreso mínimo vital o de subvenciones (paguita) para los menas, es también falso que se esté otorgando una ayuda directa de 664 euros a ningún menor de 23 años que no tenga trabajo, pero el bulo interesa a Vox para crear alarma ante la lógica de la escasez (no hay para todos; los españoles primero) junto al concepto de invasión migratoria visto anteriormente. De igual modo, es falsa la generalización y la asociación difundida permanentemente por Vox entre migrante irregular y persona de naturaleza violenta ${ }^{7}$, como demuestra aquí el equipo de Maldita respecto a uno de los tuits del corpus analizado emitido desde la cuenta oficial:

\footnotetext{
${ }^{6}$ Como se explica en la propia página, «Maldita.es es un medio sin ánimo de lucro cuyo fin es dotar a los ciudadanos de herramientas para que no te la cuelen. Maldita Hemeroteca, Maldito Bulo, Maldita Ciencia y Maldito Dato se centran en el control de la desinformación y el discurso público mediante técnicas de verificación de hechos (fact-checking) y periodismo de datos»».

7 La relación entre inmigración y delincuencia es también falsa. Como vimos en un trabajo anterior, la comunidad autónoma que más ha crecido en la última década por la llegada de inmigrantes, procedentes especialmente de Marruecos y países de Hispanoamérica, es Baleares y esto no ha conllevado en dicha comunidad un aumento correlativo de la actividad delictiva (Camargo Fernández, 2020).
} 


\section{Imagen 7. Bulos difundidos por Vox sobre la delincuencia y la violencia de los "inmigrantes ilegales"}

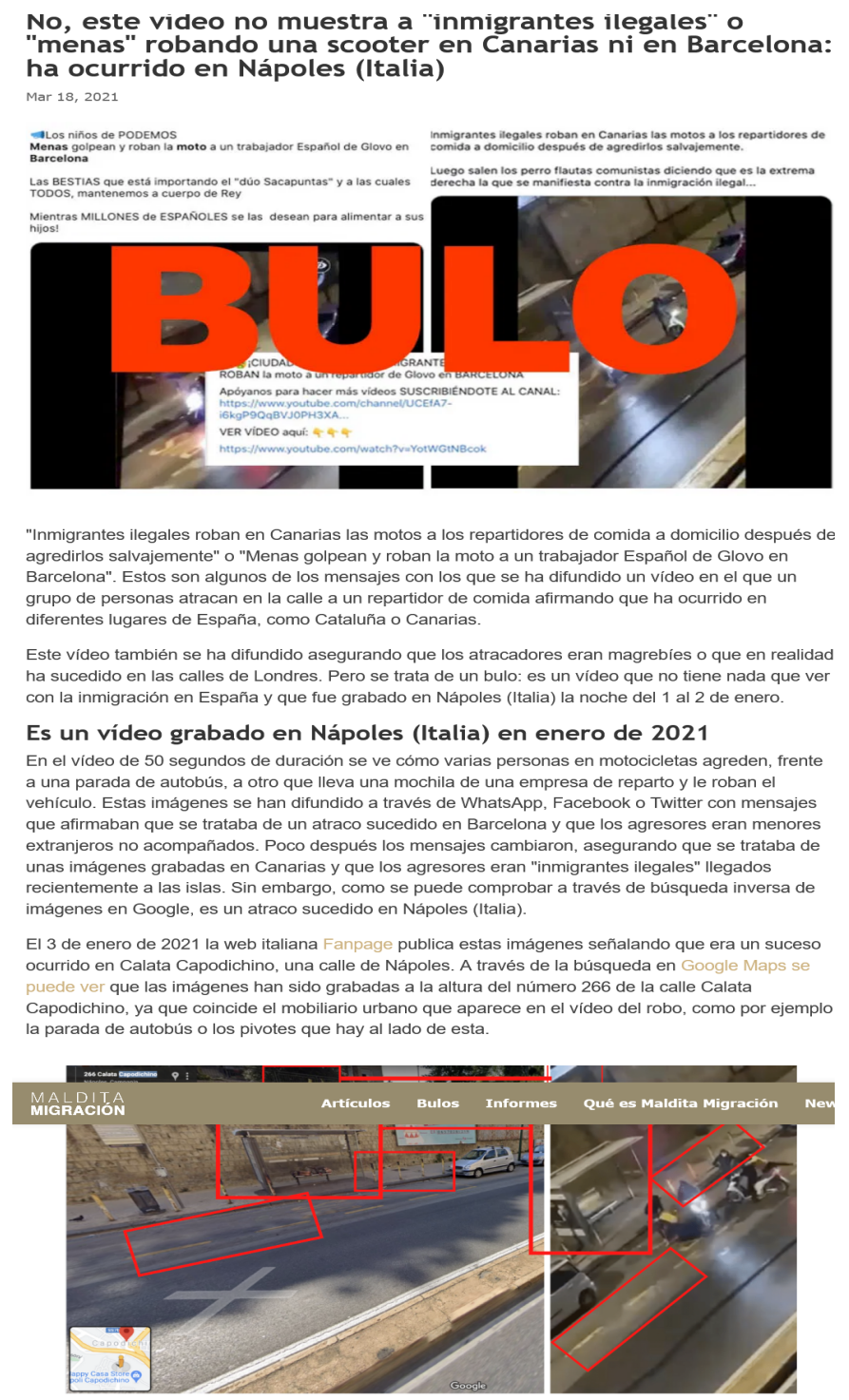

Fuente: Maldita.es. Fecha: 30/03/2021

El recurso a la fabricación de bulos para difamar y generar odio contra los migrantes tienen como consecuencia brotes de violencia como el sucedido en Gran Canaria a principio de 2021 con la cacería desatada tras la difusión por WhatsApp de una noticia falsa sobre el supuesto asesinato de un joven canario por parte de inmigrantes magrebíes. En el universo de Twitter, las informaciones falsas han supuesto suspensiones temporales y bloqueos de la cuenta de Vox y de las de varios de sus miembros más activos por parte de Twitter España, como el ya citado Rubén Pulido o Alvise Pérez, youtuber de ultraderecha. La última limitación de funciones de la cuenta@vox_es se produjo durante las elecciones catalanas, en medio de una campaña lanzada con la etiqueta \#StopIslamización en la que Vox denunciaba a los partidos políticos por haber promovido la peligrosa islamización de Cataluña. El tuit del 27 de enero de 2021 causante de la reacción de la responsable de Twitter España, Nathalie Pcquot, fue borrado del timeline de la cuenta y no forma parte por ello del corpus de este trabajo, pero ha sido recuperado a partir de las noticias publicadas al respecto: «Suponen aproximadamente un $0,2 \%$ y son 
responsables del 93\% de las denuncias. La mayoría son procedentes del Magreb. Es la Cataluña que están dejando la unánime indolencia y complicidad con la delincuencia. ¡Sólo queda VOX! $\rangle^{8}$. Como se observa, son los mismos números que aparecían en el tuit de Rubén Pulido mostrado al inicio del artículo en la reivindicación de Espinosa de los Monteros tras la suspensión temporal de la cuenta de Pulido por incitación al odio. Estos cierres o, más precisamente, suspensiones temporales de funciones de sus cuentas, son funcionales al papel de outsiders que intenta mantener el partido y a su estrategia de victimización, pues lo cierto es que Twitter suspende cada día miles de cuentas. Lo cierto es que Vox saca rédito de ello mostrándose como víctimas del sistema y volviendo siempre con mayor agresividad tras cada suspensión. El 4 de febrero de 2021, la cuenta @vox_es recuperaba todas sus funciones tras una semana de limitación y lo hacía reafirmando el mantra sobre la relación entre violencia e inmigración. El 10 de febrero de 2021, todavía en plena campaña catalana, la cuenta oficial volvía a la carga con la campaña \#BarriosSeguros, cuyo meme del menor no acompañado deshumanizado se analizó al inicio de este punto.

\section{CONCLUSIONES}

El análisis de los 262 mensajes de la muestra recogida en los perfiles con mayor número de seguidores en Twitter de Vox permite extraer una serie de conclusiones sobre el orden discursivo de esta fuerza de extrema derecha y sobre su ideario en torno a las personas migrantes. Con respecto al discurso, se ha demostrado que la cuenta desde la que más frecuentemente se emiten mensajes sobre inmigración es@vox_es $(5$ veces más), con escasa diferencias numéricas entre los otros 4 emisores. Las personalidades individuales digitales son ampliamente superadas por la del partido, demostrándose así supeditadas, con algún rasgo diferencial mínimo en el portavoz parlamentario, al mensaje de la cuenta central. En cambio, todos los emisores comparten las mismas estrategias discursivas en Twitter: sus mensajes son directos, comunicativamente agresivos, sin recurso al eufemismo, de adjetivación y nominalización simples y de colocaciones iterativas y, sobre todo, son mensajes mayoritariamente multimodales $(76,7 \%)$, con combinación de texto con vídeos, infografías, memes, fotos, noticias digitales u otros tuits insertados, a menudo de display iconoclasta para amplificar el mensaje textual (Van Leeuwen, 2015; Yus, 2019). Todo lo anterior apela a la visceralidad y la emocionalidad de los destinatarios con el fin de provocar y escandalizar, en línea con lo señalado por Martín Rojo y Elvira Ruiz (2019: 5) sobre las claves de la estrategia comunicativa de la extrema derecha española.

Asimismo, hemos constatado lo expuesto por especialistas en discurso de la altright, como Peytibi y Pérez-Diáñez (2020) respecto a la polarización y el uso del lenguaje directo con adjetivación llamativa, al analizar las colocaciones más frecuentes en los distintos ejes temáticos: inmigración ilegal, invasión migratoria, violaciones en manada, ilegales contagiados, paguita clientelar, etc. A través de los 6 ejes de carácter racista y excluyente que se repiten en los tuits del corpus, 1. Inmigrantes ilegales; 2. Menas agresores y violadores; 3 . Inmigrantes delincuentes y violentos; 4. Inmigrantes invasores; 5. Inmigrantes focos de contagio y 6 . Inmigrantes adultos y menas perceptores de subvenciones, se teje una red de discurso de temor y odio hacia ellos como fuente de delincuencia, violencia, contagio y subvenciones injustificadas. Se ha comprobado también la especial insistencia desde la cuenta de Rocío Monasterio en el eje temático de los menores, y desde la de Abascal en el eje de la invasión migratoria.

\footnotetext{
${ }^{8} \mathrm{https}$ ://www.europapress.es/nacional/noticia-vox-recupera-cuenta-twitter-arresto-semana-reafirma denuncia-violencia-inmigracion-20210204222434.html.
} 
En línea con las conclusiones señaladas por Cheddadi (2020: 70-71), la inmigración, tanto de menores como -según se ha añadido aquí- de adultos resulta un marco ideal para la defensa de un estado social nativista en el que las personas migrantes son chivos expiatorios de las desigualdades generadas por los sucesivos ajustes del modelo económico neoliberal y causantes últimas de los problemas de inseguridad en los barrios. Se evidencia también que uno de los pilares más importantes del orden discursivo de Vox es la fabricación de bulos de temática diversa para criminalizar y deshumanizar a los migrantes, generando temor y normalizando así los mensajes de odio hacia este colectivo. Su discurso es «pirotecnia discursiva desafiante que, mediante su radicalidad y excentricidad, obtiene lo que pretende: una difusión gigantesca para los mensajes, tanto por parte de los afines como de los adversarios» (Gallardo Paúls, 2019). Vox busca con estos mensajes el conflicto porque este llama la atención y provoca un gran número de reacciones; la atención que obtienen de dicho conflicto la reutilizan, finalmente, como un medio para lograr influencia. En este sentido, hemos explicado que la habitual suspensión de funciones de sus cuentas por parte de Twitter es algo buscado por el partido para dar imagen de víctimas del sistema y aparecer como outsiders.

Finalmente, en las citadas investigaciones de Martín Rojo y Van Dijk (1998) y de Rubio Carbonero (2011), se mostraba cómo en la comunicación política del Partido Popular sobre los inmigrantes ya era habitual la presentación negativa de los inmigrantes frente a la presentación positiva de los españoles. Estos trabajos indican que la lógica de polarización en grupos, nosotros (el endogrupo) y ellos (el exogrupo) a través de la que se enfatizan los aspectos positivos del primero y se exacerban los aspectos negativos del segundo, creando estereotipos y estigma, no constituye una innovación de Vox, sino que estaba ya enraizada en su partido matriz.

Respecto a las limitaciones de este estudio, al filtrar en la búsqueda avanzada por las palabras inmigración, inmigrantes y menas, han quedado excluidas las campañas explícitamente islamófobas, así como otras colocaciones de alto contenido xenófobo muy frecuentes en el orden discursivo de Vox, como estercolero multicultural. Queda pendiente para futuras investigaciones el análisis de estas campañas, de los hashtags empleados, de otras colocaciones recurrentes, así como del valor de los diminutivos despectivos habituales en la comunicación de este partido. Por último, en el plano de las aportaciones, este trabajo ha demostrado cómo la aplicación de una metodología mixta, cualitativa y cuantitativa (Wodak y Meyer, 2001; Pardo Abril, 2013) resulta óptima no solo para las investigaciones del análisis crítico del discurso, sino también para las del análisis del discurso político multimodal.

\section{REFERENCIAS BIBLIOGRÁFICAS}

Acha Ugarte, Beatriz. 2021. Analizar el auge de la ultraderecha. Surgimiento, ideología y ascenso de los nuevos partidos de ultraderecha. Colección Más Democracia. Barcelona: Gedisa.

Alonso, Ana. 2020. «Por qué la extrema derecha comunica mejor y llega cada vez a más gente. Entrevista a Xavier Peytibi y Sergio Pérez-Diáñez, autores de Cómo comunica la alt-right. De la rana Pepe al virus chino». El Indepediente, 19/07/2020.

Alonso, Sonia y Cristóbal Rovira Kaltwasser. 2015. «Spain: No country for the populist radical right?». South European Society and Politics, 20-1: 21-45.

Alonso-Muñoz, Laura, Susana Miquel-Segarra y Andreu Casero-Ripollés. 2016. «Un potencial comunicativo desaprovechado. Twitter como mecanismo generador de 
diálogo en campaña electoral». Obra Digital, 11: 39-58. http://dx.doi.org/10.25029/od.2016.100.\%25x.

Bañón Hernández, Antonio M. 2002. Discurso e inmigración. Propuestas para el análisis de un debate social. Murcia: Universidad de Murcia.

Barrios Rodríguez, María Auxiliadora. 2015. Las colocaciones del español. Madrid: Arco/Libros.

Bello Reguera, Gabriel. 2008. «De la demonización al racismo (sobre la deshumanización del otro)». Criterio Jurídico, 8-2: 9-24.

Camargo Fernández, Laura. 2020. «Inmigración y comunidades lingüísticas en Baleares (1990-2019)», IX Jornadas Internacionales de Lingüistica Hispánica. Lazos y distancias, Lisboa, 20-22 de abril de 2020.

Casero-Ripollés, Andreu. 2007. «Discurso mediático, inmigración e ilegalidad: legitimando la exclusión a través de las noticias». En Discursos sobre la inmigración en España, los medios de comunicación, los parlamentos y las administraciones, eds. Ricard Zapata y Teun A. Van Dijk (pp. 69-92). Barcelona: Fundación CIDOB.

Casero-Ripollés, Andreu. 2009. «El control político de la información periodística». Revista Latina de Comunicación Social, 64: 354-366. http://www.revistalatinacs.org/09/art/29_828_47_ULEPICC_08/Andreu_Casero. html.

Castro Martínez, Paloma y Diego Mo Groba. 2020. «El issue de la inmigración en los votantes de VOX en las Elecciones Generales de noviembre de 2019». RIPS, 191: 39-58. https://doi.org/10.15304/rips.19.1.6947.

Cervi, Laura. 2020. «Exclusionary Populism and Islamophobia: A Comparative Analysis of Italy and Spain». Religions, 11, 516. https://doi.org/10.3390/rel11100516.

Checa y Olmos, Francisco. 2020. «Miedo y comunicación en tiempos de pandemia. De las fake-news al humor». En Cambio y coronavirus. Representaciones sociales. Burla, silencio y miedo, coords. Carmen Vázquez Domínguez, Beatriz PérezGonzález y Diana Salzano (pp. 29-44). Madrid: McGraw Hill.

Cheddadi, Zakariae. 2020. «Discurso político de Vox sobre los Menores Extranjeros No Acompañados». Inguruak, 69: 57-77. https://doi.org/10.18543/inguruak-692020-art04.

Del Teso, Enrique. 2020. «Cómo tratar con la propaganda fascista sin futuro ni pasado». LaU. $\quad$ https://la-u.org/como-tratar-con-la-propaganda-fascista-sin-futuro-nipasado/.

Fanjul, Gonzalo e Ismael Gálvez-Iniesta. 2020. Extranjeros, sin papeles $e$ imprescindibles: una fotografía de la inmigración irregular en España. Madrid: Fundación porCausa, Universidad Carlos III de Madrid. https://porcausa.org/wpcontent/uploads/2020/07/RetratodelairregularidadporCausa.pdf.

Fernández Riquelme, Pedro. 2020. «Identidad y nostalgia. El discurso de Vox a través de tres eslóganes». Sabir. International Bulletin of Applied Linguistics, 1-2: 77-114. http://ojs.ual.es/ojs/index.php/IBAL/article/view/3582/3997.

Ferreira, Carles. 2019. «Vox como representante de la derecha radical en España: un estudio sobre su ideología». Revista Española de Ciencia Política, 51: 73-98. https://doi.org/10.21308/recp.51.03.

Gallardo Paúls, Beatriz. 2019. «Vox: el discurso enmascarado». Agenda Pública, 12/04/2019. https://agendapublica.es/vox-el-discurso-enmascarado/.

González Enríquez, Carmen. 2017. «La excepción española: el fracaso de los grupos de derecha populista pese al paro, la desigualdad y la inmigración». Documento de trabajo 7/2017, Real Instituto Elcano. 
http://www.realinstitutoelcano.org/wps/wcm/connect/155407f2-773a-4f08-ad08aff2df759fdb/DT7-2017-GonzalezEnriquez-Excepcion-espanola-fracaso-gruposderecha-populista.pdf?MOD=AJPERES\&CACHEID=155407f2-773a-4f08ad08-aff $2 \mathrm{df} 759 \mathrm{fdb}$.

Hernández Conde, Macarena y Manuel Fernández García. 2019. «Partidos emergentes de la ultraderecha: ¿fake news, fake outsiders? Vox y la web Caso Aislado en las elecciones andaluzas de 2018». Teknokultura, 16-1: 33-53. http://dx.doi.org/10.5209/TEKN.63113.

Jungherr, Andreas. 2016. «Twitter use in election campaigns: A systematic literature review». Journal of Information Technology \& Politics, 13-1: 72-91. https://doi.org/10.1080/19331681.2015.1132401.

Mancera Rueda, Ana. 2020. «La movilización política en Twitter, una red para "pescar" votos». Pasajes, 59: 31-45. https://mobiroderic.uv.es/bitstream/handle/10550/76567/7550104.pdf?sequence $=1$ \&isAllowed $=\mathrm{y}$.

Martín Rojo, Luisa y Teun A. Van Dijk. 1998. «"Había un problema y se ha solucionado”. Legitimación de la Expulsión de Inmigrantes "Ilegales" en el Discurso Parlamentario Español». En Poder-Decir, o el poder de los discursos, eds. Luisa Martín Rojo y Rachel Whittaker (pp. 169-234). Madrid: Arrecife.

Martín Rojo, Luisa y Paloma Elvira Ruiz (coords.). 2019. «EDiSo ante los desafíos discursivos de nuestro tiempo: herramientas para neutralizar el fascismo universal». Sesión plenaria colectiva. IV Simposio Internacional EDiSo. Voces, silencios y silenciamientos en los estudios del discurso. Universidade de Santiago de Compostela, 5-7 junio de 2019.

Méndez Santos, Carmen. 2020. «La construcción de la identidad lingüística de Santiago Abascal en Twitter». Revista Estudios del Discurso Digital (REDD), 3: 50-77. https://doi.org/10.24197/redd.3.2020.50-77.

Mudde, Cas. 2007. Populist Radical Right Parties in Europe. Cambridge: Cambridge University Press.

Nagle, Angela. 2018. Muerte a los Normies. Las guerras culturales en internet que han dado lugar al ascenso de Trump y la alt-right. Trad. Hugo Camacho. Barcelona: Orciny Press.

Norris, Pippa. 2005. Radical Right. Voters and Parties in the Electoral Market. Cambridge: Cambridge University Press.

Pardo Abril, Neyla Graciela. 2013. Cómo hacer análisis crítico del discurso. Una perspectiva latinoamericana. Bogotá: Universidad Nacional de Colombia.

Peytibi, Xavier y Sergio Pérez-Diáñez. 2020. Cómo comunica la alt-right. De la rana Pepe al virus chino. Barcelona: Ediciones Beers\&Politics.

Ramos, Miquel (coord.). 2021. De los neocón a los neonazis. La derecha radical en el Estado español. Madrid: Liasion Office. Rosa Luxemburg Stiftung. https://www.rosalux.eu/es/article/1927.de-los-neoc\%C3\%B3n-a-losneonazis.html.

Rubio Carbonero, Gema. 2011. «Representación social de la inmigración en el discurso del Partido Popular». Cultura, Lengua y Representación, Número Especial Sobre Discurso Político, IX: 173-99. https://doi.org/10.6035/CLR.2011.9.8.

Rubio-Pueyo, Vicente. 2019. Vox ¿Una nueva extrema Derecha en España? New York Office. Rosa Luxemburg Stiftung. https://rosalux.nyc/wpcontent/uploads/2021/01/RLS-NYC_VOX_Spain_ES.pdf 
Santamarina, Ana. 2020. «The Spatial Politics of Far-right Populism: VOX, Anti-fascism and Neighbourhood Solidarity in Madrid City». Critical Sociology. https://doi.org/10.1177/0896920520962562.

Terrasa, Rodrigo. 2019. «De Bolsonaro a Vox: cómo WhatsApp ha llegado a ser el arma más eficaz de propaganda política». El Mundo, 6/01/2019. https://www.elmundo.es/papel/historias/2019/01/05/5c2f91a8fc6c834e478b45dc .html.

Urbán, Miguel. 2019. La emergencia de Vox. Apuntes para combatir a la extrema derecha española. Colección Crítica \& Alternativa. Barcelona: Sylone/Viento Sur.

Vampa, Davide. 2020. «Competing forms of populism and territorial politics: the cases of Vox and Podemos in Spain». Journal of Contemporary European Studies, 283: 304-321. https://doi.org/10.1080/14782804.2020.1727866.

Van Dijk, Teun, A. 2000. «Ideologies, Racism, Discourse: Debates on immigration and ethnic issues». En Comparative perspectives on racism, eds. Jessika ter Wal y Maykel Verkuyten (pp. 91-116). Aldershot: Ashgate.

Van Dijk, Teun, A. 2003. Racismo y discurso de las élites. Trad. Montse Basté. Barcelona: Gedisa.

Van Leeuwen, Theo. 2015. «Multimodality». En The Handbook of Discourse Analysis, eds. Deborah Tannen, Heidi E. Hamilton y Deborah Schiffrin. $2^{a}$ edición (pp. 447465). Oxford: Wiley Blackwell.

Vox. 2018. 100 medidas para la España viva. https://www.voxespana.es/noticias/100medidas-urgentes-de-vox-para-espana-20181006.

Vox. 2019. Manual de Comunicación. $1^{\mathrm{a}}$ edición. https://www.eldiario.es/politica/manual-comunicacion-vox-rechazarentrevistas_1_1592948.html.

Wodak, Ruth. 2015. The politics of fear: What right wing populist discourses mean. London: Sage.

Wodak, Ruth y Michael Meyer. 2001. Methods of Critical Discourse Analysis. London: Sage.

Yus, Francisco. 2019. «Multimodality in memes. A cyberpragmatic approach». En Analyzing Digital Discourse. New Insights and Future Directions, eds. Patricia Bou-Franch y Pilar Garcés-Conejos Blitvich (pp. 105-131). London: Palgrave MacMillan. 